\title{
SEISMIC RETROFIT OF EXISTING BUILDINGS LED BY NON-LINEAR DYNAMIC ANALYSES
}

\author{
MARIA CRISTINA PORCU ${ }^{1}$, JUAN CARLOS VIELMA ${ }^{2}$, FRANCESCO PANU ${ }^{3}$, CLAUDIA AGUILAR ${ }^{2}$, \\ \& GIUSEPPE CURRELI ${ }^{3}$ \\ ${ }^{1}$ University of Cagliari, Cagliari, Italy. \\ ${ }^{2}$ Pontificia Universidad Catolica de Valparaiso, Valparaiso, Chile. \\ ${ }^{3}$ MSc Civil Engineer - independent researcher, Italy.
}

\begin{abstract}
Although still little used in practice, the non-linear time-history (NLTH) analysis is the most powerful method to design new earthquake-resistant buildings. This kind of analysis may even help the designer to assess the seismic performance of existing buildings and suitably plan their retrofit. With reference to a pre-seismic-code r/c building and to a suite of Italian spectrum-consistent earthquakes, the paper highlights the advantages of adopting NLTH analyses to evidence critical features in the seismic response of existing buildings and to assess in advance the effectiveness of their retrofit strategy. To this purpose, the behaviour of the retrofitted building should be suitably modelled. This paper shows how this can be done when carbon fibre reinforced polymer is used to strengthen the critical sections. Two advanced finite element programmes are adopted in parallel to carry out the numerical analyses: SAP2000 and SeismoStruct. The differences involved in the numerical model are discussed and the main advantages of a three-step procedure based on the NLTH approach are evidenced.

Keywords: FRP reinforcement, non-linear dynamic analysis, seismic retrofit of $r / c$ buildings, ductility.
\end{abstract}

\section{INTRODUCTION}

A large part of the buildings located in highly seismic countries like Italy or Chile was built before the 80s of the last century. This means that they were designed according to obsolete codes without seismic regulations. It is of great relevance hence to assess the seismic behaviour of these pre-seismic-code buildings and to plan their seismic retrofit. A very effective way to carry out this assessment is to simulate the response of the building under real earthquakes. This can be done through a non-linear time-history (NLTH) analysis. Despite being the most powerful kind of seismic analysis, the NLTH analysis is still scarcely adopted in practice, not only for the assessment of existing buildings but even for the design of new structures [1-3].

While different approaches can be exploited to improve the seismic behaviour of buildings as, for instance, base isolation [4], partial mass isolation [5-6] or passive dissipative systems [7-8], the approach currently most used in earthquake engineering is in fact that of ensuring the building has enough ductility resources to dissipate seismic energy and avoid brittle failure [9]. When r/c moment resisting buildings are concerned, this can be achieved through the fulfilment of strength hierarchy rules and the care in reinforcement detailing, as required by current codes [10]. Buildings designed before the development of modern seismic codes, however, hardly meet these requirements. A suitable improvement of the ductile behaviour of pre-seismic-code moment resisting $\mathrm{r} / \mathrm{c}$ frames can be achieved by confining the critical zones of structural members, where plastic hinges are expected to develop, through carbon fibre reinforced polymers (CFRPs) [11], which are also able to improve the section strength.

With reference to a r/c framed building designed according to the Italian pre-seismic standard, this paper shows how the NLTH analysis may be effective in (i) assessing the seismic performance of existing structures; (ii) highlighting undesirable collapse mechanisms (for instance, the soft-storey one); (iii) quantifying the earthquake ductility demand; (iv) detecting 
structural elements needing to be reinforced and (v) checking in advance the behaviour of the retrofitted building.

A suite of spectrum-consistent earthquakes relevant to a high-seismicity Italian site is considered in the study. A non-linear model of the building is assumed while two advanced finite element programmes, SAP2000 [12] and SeismoStruct [13], are used to perform the nonlinear analyses. A concentrated-plasticity model is adopted in SAP2000 while fibre-based finite elements are introduced in SeismoStruct to simulate the plastic behaviour of the critical sections of the structure. Both the concentrated plasticity and the fibre-based approaches are in fact adopted in the literature to perform pseudo-static and dynamic time-history seismic analyses [2-3, 14-17].

The seismic retrofit of the building is assumed to be made with CFRP materials. While the possibility to introduce FRP reinforcement is internally implemented in SeismoStruct, an external study should be carried out to give SAP2000 the properties of the CFRP reinforced sections. A comparison between the results obtained from the two computer programmes is provided while a three-step procedure for the seismic retrofit of $\mathrm{r} / \mathrm{c}$ existing buildings led by NLTH analyses is presented.

\section{CASE STUDY: PRE-SEISMIC-CODE BUILDING}

A two-storey $\mathrm{r} / \mathrm{c}$ framed building, assumed to be built in Italy in the $80 \mathrm{~s}$ of the last century, was considered in the study, see Fig. 1. The building was designed according to the old 1976 Italian regulation [18], which did not provide anti-seismic guidance. Some details of the building are provided in Fig. 1.

The building was modelled with both SAP2000 and SeismoStruct to carry out parallel analyses and compare results. A lamped-plasticity 3D model of the building was adopted in SAP2000 while a distributed plasticity fibre-based 3D model was considered with SeismoStruct. Rigid diaphragm constraints are assumed at slabs while slab masses were assigned to the beams. According to Section 3.2.4 of EC8 [10], the combination of actions $G_{1}+G_{2}+\psi_{2 i} Q_{k i}$ was considered to evaluate the seismic masses, where $G_{1}, G_{2}$, and $Q_{k i}$ denote structural loads, non-structural permanent loads and variable actions, respectively; while $\psi_{2 i}$ is a coefficient taking into account the likelihood of variable actions. The masses associated to non-structural loads and to variable actions are listed in Table 1 (structural masses are internally calculated by the FEM programmes). A Rayleigh classic damping model was assumed and a constant value damping ratio $\xi=5 \%$ was assumed for each mode.

\subsection{Non-linear model of the building with SAP2000}

A lamped-plasticity 3D model was adopted in SAP2000, where non-linear frame hinge elements were put at the end of all elements to account for the plastic rotation of extreme sections. A parametric P-M2-M3 nonlinear frame hinge element that can couple the behaviour in the axial and bending directions was chosen to model the extreme sections of columns while M3 hinge elements were adopted for beams. Based on FEMA-356 [19], the forcedisplacement model of the r/c hinge elements given in Fig. 2a, which is assumed by default by SAP2000, see Fig. 2b, was adopted in the present investigation, since no specific plastic-hinge model is provided by EC8. The values to be assigned to points $\mathrm{B}, \mathrm{C}, \mathrm{D}$ and $\mathrm{E}$ in Fig. 2 vary depending on the type of element, kind of materials, longitudinal steel percentage and axial load level. A Takeda behaviour was assumed for concrete and a Kinematic behaviour for reinforcement steel. 


\section{D Model}
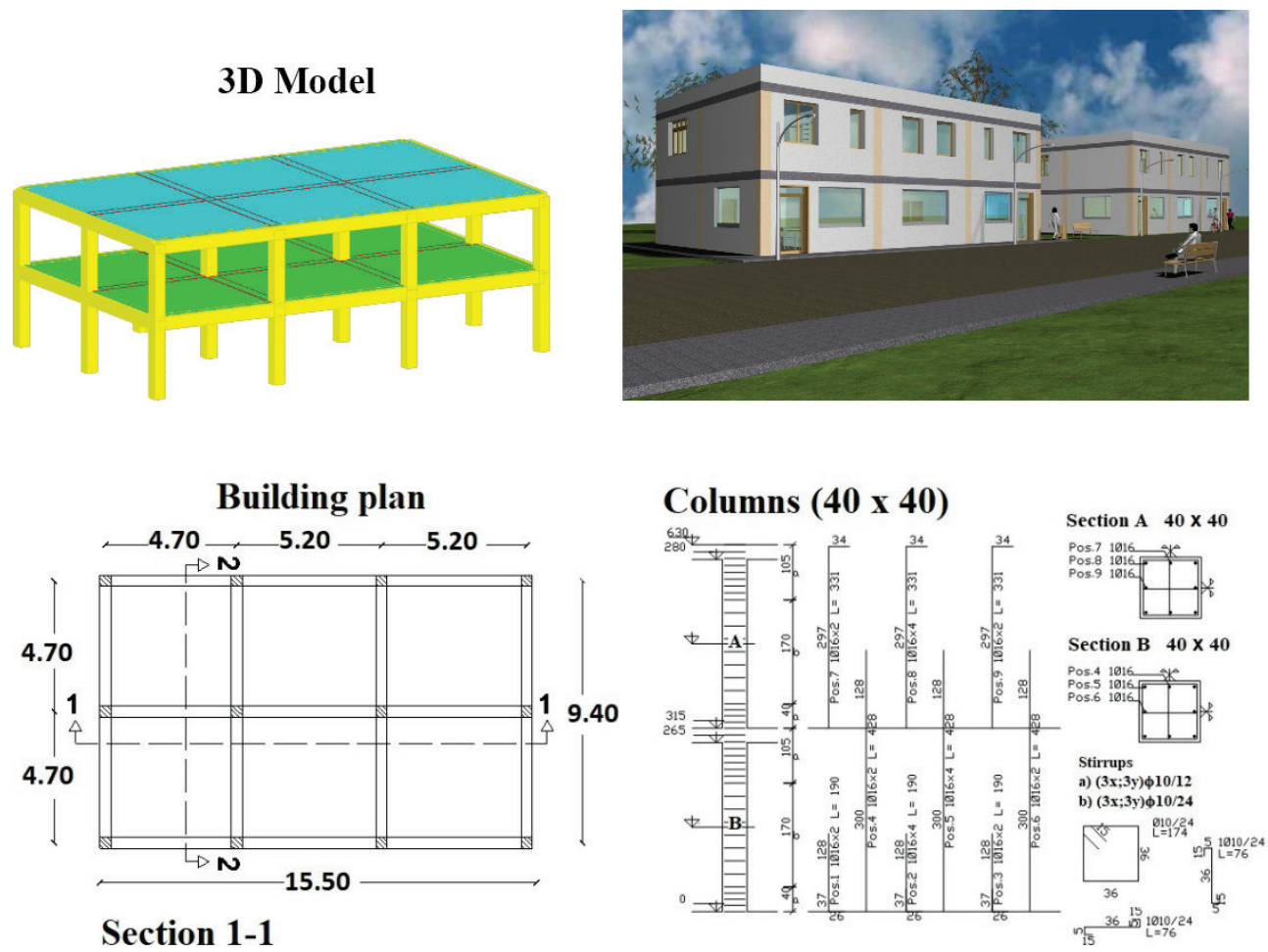

Section 1-1

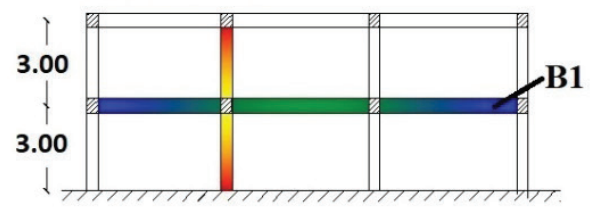

\begin{tabular}{|c|c|c|}
\hline material & $\boldsymbol{R}_{\text {ck }}\left(\mathrm{N} / \mathrm{mm}^{2}\right)$ & $\boldsymbol{E}\left(\mathrm{N} / \mathrm{mm}^{2}\right)$ \\
\hline Concrete C20/25 & 25 & 30200 \\
\hline Steel FeB44k & 430 & 20600 \\
\hline
\end{tabular}

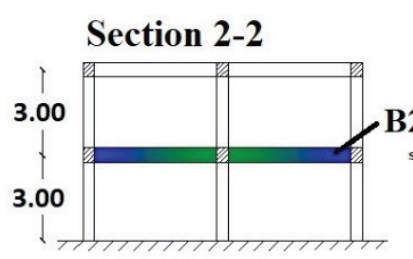

B2

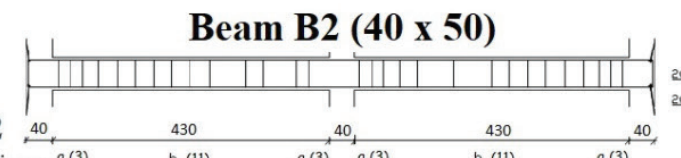

Section
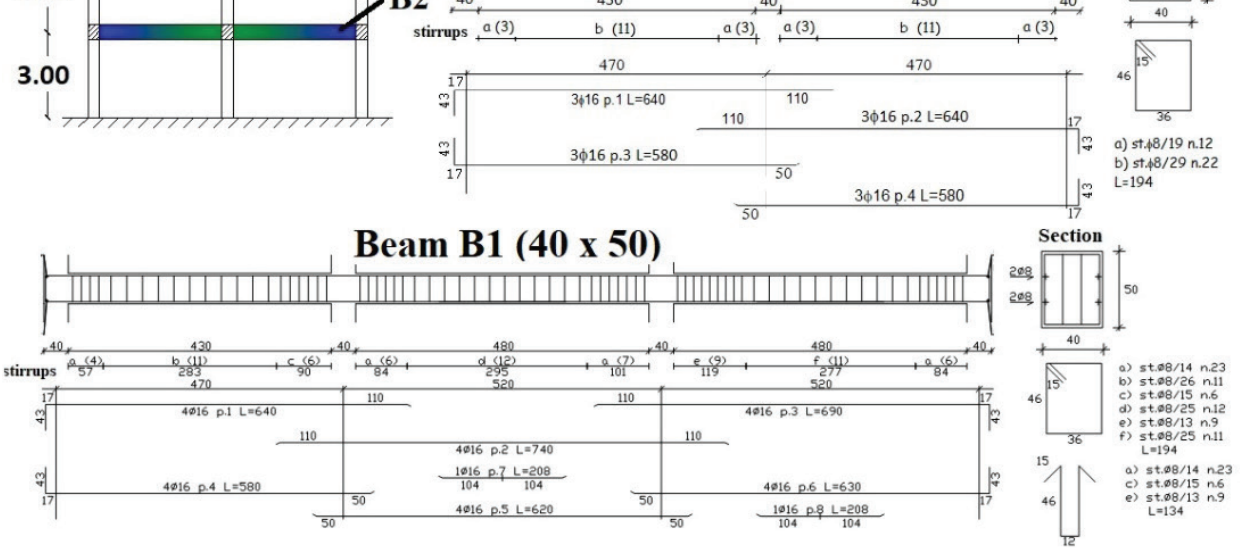

Figure 1: Case study: pre-seismic-code r/c building. 
Table 1: Masses associated to non-structural loads and variable actions.

\begin{tabular}{lccccc}
\hline & $\begin{array}{c}\text { Non-structural } \\
\text { load }(\mathbf{k P a})\end{array}$ & $\begin{array}{c}\text { Non- structural } \\
\text { mass }\left(\mathbf{k g} / \mathbf{m}^{\mathbf{2}}\right)\end{array}$ & $\begin{array}{c}\text { Variable load } \\
\mathbf{( k P a )}\end{array}$ & $\psi_{2}$ & $\begin{array}{c}\text { Variable mass } \\
\left(\mathbf{k g} / \mathbf{m}^{2}\right)\end{array}$ \\
\hline Slab & 6.25 & 637 & 2.00 & 0.3 & 61.16 \\
Roof & 6.25 & 637 & 0.50 & 0.3 & 15.00 \\
\hline
\end{tabular}

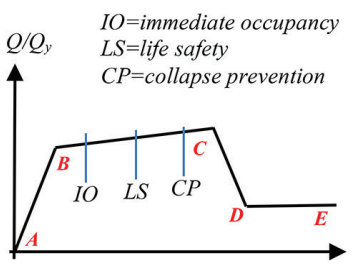

(a)

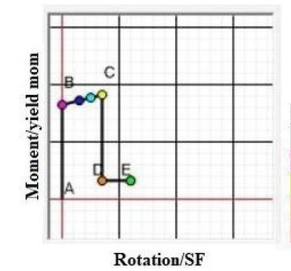

(b)

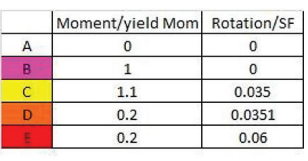

Figure 2: (a) FEMA-356 plastic hinge behaviour and (b) moment vs rotation for pillars' hinges in the SAP2000 model (PM2M3 hinge).

\subsection{Non-linear model of the building with SeismoStruct}

A fibre-based finite element approach was adopted to model the building with SeismoStruct. The hysteretic behaviour assumed for concrete and reinforcement steel is provided in the diagrams of Fig. 3. As well known, an adequate discretization of the structural members is typically needed in the fibre-based finite element approach to capture the behaviour of those structural parts in which a stress concentration is anticipated, as is the case with the ends of beams and columns in ductile-framed-buildings. The discretization at the section level is preliminary to generate the fibres of the model. To this purpose, the sections of the columns and the beams of the considered building were divided into different areas whose forms end up completely covering the cross section of the element, see Fig. 4.
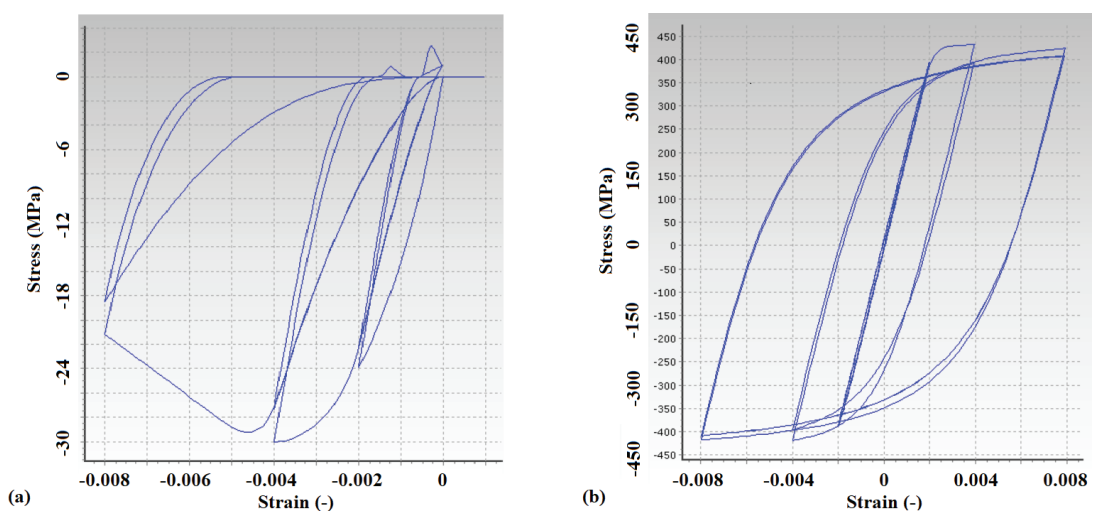

Figure 3: Constitutive relationships for (a) concrete and (b) reinforcement steel. 


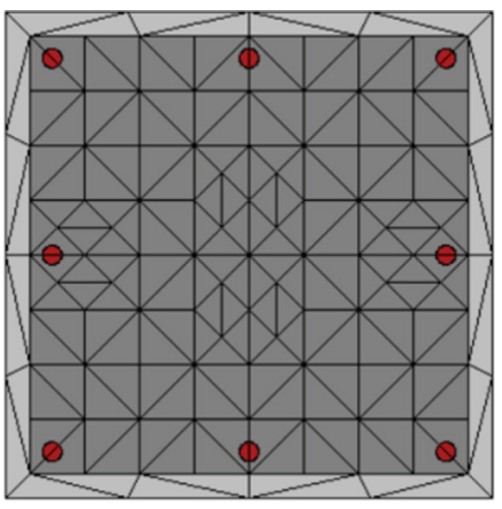

(a)

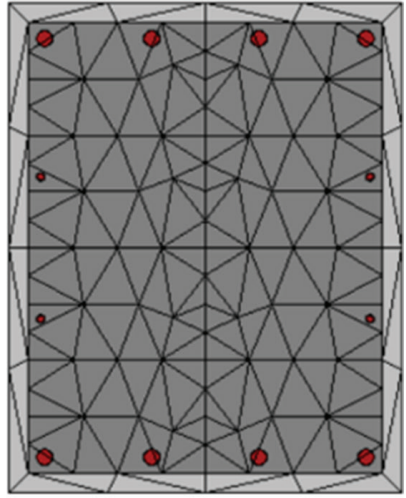

(b)

Figure 4: Sectional discretization of (a) columns and b) beams in SeismoStruct (not to scale).

\section{SUITES OF SPECTRUM-CONSISTENT EARTHQUAKES}

According to EC8 [10; 3.2.3.1.2, (4)], a suite of at least three ground acceleration time histories consistent with the reference spectrum should be set to carry out an NLTH analysis. By referring to the target response spectrum relevant to the town of Messina (Sicily, Italy), see Fig. 5a, a suite of seven recorded spectrum-compatible acceleration time histories was considered in the present investigation, as obtained through the software REXEL [20], see Table 2. The spectra of the $x$ and $y$ components of the seven earthquakes are given in Fig. 5b while the time-histories of the $x$ components are plotted in Fig. 5c (the time-histories of the $y$ components are not displayed herein for brevity). Reference to the European Strong Motion Database (ESD) [21] was made by assuming a magnitude range $5 \leq M_{w} \leq 7$ and an epicentre

(a)
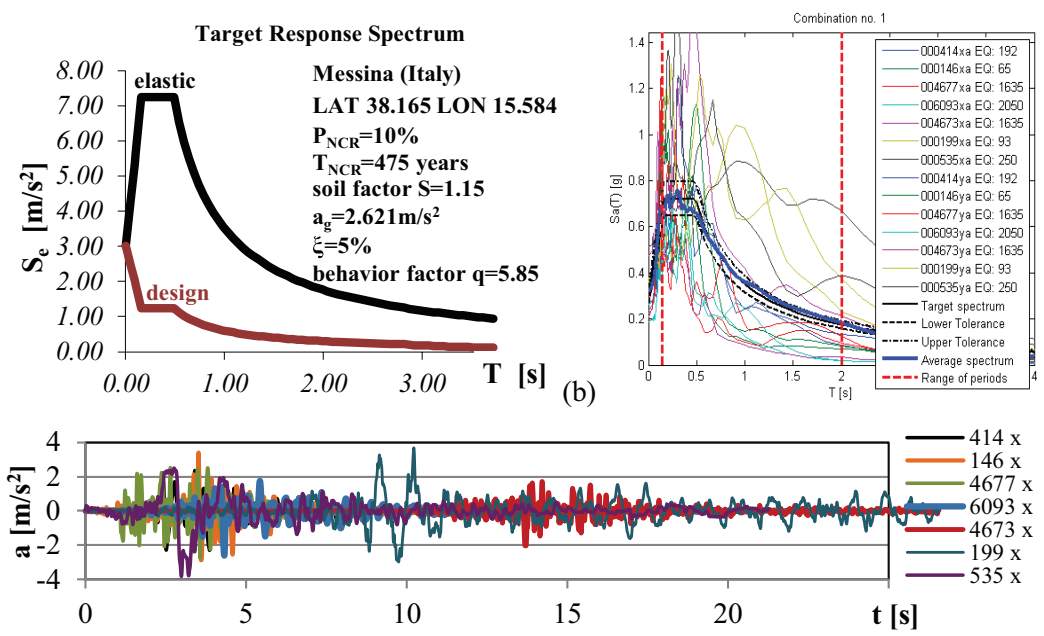

Figure 5: (a) Target elastic and design response spectra; (b) spectra of the suite of $x$ and $y$ spectrum-consistent earthquakes and (c) time-histories of the seven earthquakes ( $x$ components). 
Table 2: Suite of earthquakes consistent with the Messina elastic spectrum in Fig. 5a.

\begin{tabular}{|c|c|c|c|c|c|c|}
\hline Waveform ID & Earthq. ID & Station ID & Place & Date & Mw & $\Delta[\mathbf{k m}]$ \\
\hline 414 & 192 & ST163 & Kalamata & $13 / 09 / 86$ & 5.9 & 11 \\
\hline 146 & 65 & ST24 & $\begin{array}{c}\text { Friuli } \\
\text { (aftershock) }\end{array}$ & $15 / 09 / 76$ & 6 & 14 \\
\hline 4677 & 1635 & ST2562 & $\begin{array}{l}\text { South } \\
\text { Iceland }\end{array}$ & $17 / 06 / 00$ & 6.5 & 21 \\
\hline 6093 & 2050 & ST1372 & $\begin{array}{c}\text { Kozani } \\
\text { (aftershock) }\end{array}$ & $19 / 05 / 95$ & 5.2 & 16 \\
\hline 4673 & 1635 & ST2482 & $\begin{array}{l}\text { South } \\
\text { Iceland }\end{array}$ & $17 / 06 / 00$ & 6.5 & 15 \\
\hline 199 & 93 & ST67 & Montenegro & $15 / 04 / 79$ & 6.9 & 16 \\
\hline 535 & 250 & ST205 & Erzincan & $13 / 03 / 92$ & 6.6 & 13 \\
\hline
\end{tabular}

distance $\Delta \leq 20 \mathrm{~km}$. Upper and lower tolerated deviation of the average spectrum from the target spectrum were both set to $10 \%$. It can be noted, incidentally, that only the lower deviation is specified by EC8 (it should not exceed 10\%) while no indication about the upper deviation is provided, although the choice of the upper bound for the average spectrum might strongly affect the results of the analysis as discussed in [3].

\section{NLTH ANALYSIS TO LEAD THE SEISMIC RETROFIT OF A BUILDING}

Founded on successive NLTH analyses under spectrum-consistent earthquakes, a 3-step procedure can be followed to seismically retrofit a building. The procedure allows (1) assessing the seismic performance of the pre-seismic-code building, by highlighting any likely sub-standard behaviour of its members; (2) adopting a suitable retrofit strategy based on the findings of the first step; (3) checking the effectiveness of the retrofit strategy by assessing the seismic behaviour of the post-retrofit building. With reference to the case-study building, these steps are described in detail below.

\subsection{Step 1: highlight any sub-standard behaviour of the pre-seismic-code building}

NLTH analyses were carried out to assess the behaviour of the case-study building under the Messina spectrum-consistent earthquakes (see Fig. 5 and Table 2) by means of SAP2000 and SeismoStruct. The deformed shape obtained through SAP2000 under the strongest earthquake of the suite is plotted in Fig. 6a, where the colours of the plastic hinges are congruent with the performance scale alongside. Although the collapse prevention performance level (CP in the scale in Fig.6) is never reached in the considered instances, the cyan coloured plastic hinges denote severe damage at the final sections of the ground floor columns, thus evidencing a soft-storey mechanism. The same undesired failure mode was evidenced by the non-linear analyses carried out with SeismoStruct, see Fig. 7a.

As the time-history analysis progresses within the elements, the stresses that establish the threshold for certain conditions such as the yield of the longitudinal bars, the cracking of the concrete of the unconfined zone, the cracking of the concrete of the confined core and the fracture of longitudinal bars, can be reached. However, one of the most common criteria in 
(a) Pre-retrofit
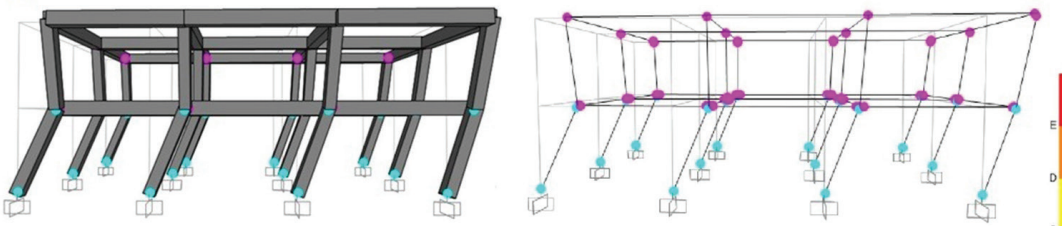

(b) Post-retrofit
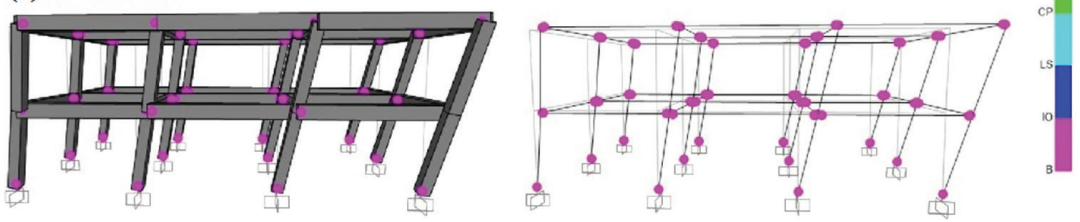

Figure 6: Deformed shape and plastic hinges of the (a) pre-retrofit and (b) post-retrofit building under the strongest earthquake of the suite (as obtained by Sap2000).

(a) Pre-retrofit

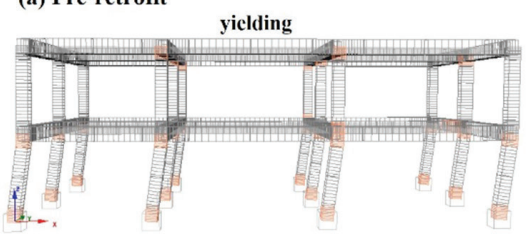

(b) Post-retrofit

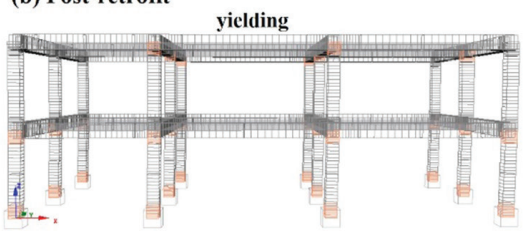

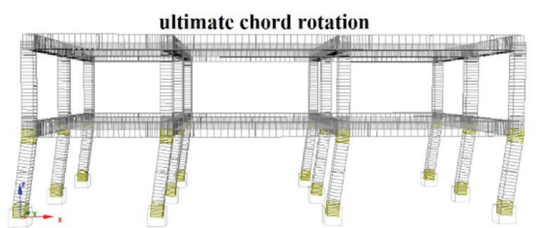

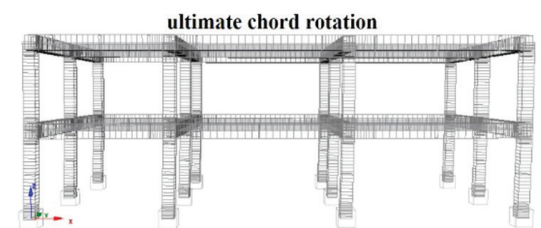

Performance criteria

■ Crush confined $\mathbf{\square}$ Yield $\mathbf{\square}$ Crush unconfined $\boldsymbol{\square}$ Fracture

Chord rotation $\mathbf{S}$ Shear failure

Figure 7: Deformed shape, yielding and ultimate chord rotation in the (a) preretrofit and (b) post-retrofit building (as obtained by SeismoStruct).

earthquake-resistant engineering is to compare the rotation of the structural elements with a certain limit value, in order to obtain the damage achieved by these elements. On the right of Fig. 7a the deformed shape and ultimate chord rotation achieved by the elements of the building when subjected to the seismic action in the $x$-direction is shown. As can be observed, some of the elements of the pre-retrofit building overcome the ultimate chord rotation of the element. Based on these results, it is possible to know which members of a structure need to be retrofited.

\subsection{Step 2: adopt a retrofit strategy to improve the seismic performance of the building}

The soft-storey behaviour of the pre-retrofit building is due to the unfulfilment of the "strong columns/weak beams" capacity design rule prescribed by the modern seismic codes. While the 
hierarchy of resistance rule that avoid brittle shear failure was in fact found to be fulfilled by any member of the pre-retrofit building, the EC8 hierarchy rule [10], recalled in Eq. (1), linking the strength moments of columns $\left(M_{R c i}\right)$ and beams $\left(M_{R b i}\right)$ through an overstrength factor $\left(\gamma_{R d}\right.$ $=1.3$ ) was not met instead.

$$
\sum M_{R c} \geq \gamma_{R d} \sum M_{R b}
$$

To overcome such an inadequacy, the flexural strength of the final sections of the ground-floor columns should be properly increased to allow plastic hinges to develop at the end of the beams instead of developing at the end of columns. The achievement of the desired ductility for the whole building (and consequently of its critical regions) as well as the fulfilment of the strength hierarchy rules is pursued by the modern seismic codes through many prescriptive detailing rules that are generally not met by pre-seismic-code buildings.

Since the $\mathrm{r} / \mathrm{c}$ detailing features can be hardly modified after the construction of a building, to improve the seismic behaviour of existing buildings, a suitable retrofit strategy should be adopted in the perspective of the capacity design philosophy. In the present investigation the top sections of all the ground-floor columns are assumed to be strengthened by means of wrapping CFRP sheets, which is known to improve both ductility and strength of r/c sections. After a preliminary study over different kind of FRP reinforcements, the Mapewrapt C UNIAX-HM 600 provided by MAPEI [21] was finally chosen, see Table 3.

\subsection{Step 3: assess the seismic performance of the post-retrofit building}

Many techniques are available to improve the behaviour of existing buildings and, whatever the choice, the NLTH analysis might be very useful to assess the effectiveness of the strategy adopted. To this purpose, an FEM model of the reinforced building should be implemented to carry out the NLTH analysis. Only some structural FEM software packages, however, allow the user to implement internally the FRP reinforcement of $r / c$ sections. Among them is SeismoStruct, while, on the contrary, SAP2000 does not presently cover FRP reinforcement simulations.

\subsubsection{SAP2000}

A lengthy procedure was necessary to model the retrofitted building with SAP2000, which involved (1) a preliminary external analysis to calculate the moment-curvature diagrams through the software BIAXIAL [22]; (2) a trial and error procedure to find the interaction diagram of the CFRP-reinforced column sections and (3) the manual entry of the data of the plastic hinges at the top of the ground-floor columns so as to simulate the presence of CFRP reinforcement. Fig. 8 provides an instance of the pre-retrofit and post-retrofit behaviour of the column sections, as obtained with SAP2000. With reference to the seven earthquakes given in Table 2 and Fig. 5, the seismic performance of the post-retrofit building was assessed by means of NLTH analyses carried out through SAP2000. The post-retrofit deformed shape is provided in Fig. $6 \mathrm{~b}$ where the plastic hinges are also evidenced. A comparison with the pre-retrofit global behaviour of the building (Fig. 6a) shows that the soft-storey mechanism is no longer exhibited while plastic hinges stay within the immediate occupancy zone.

Table 3: Characteristics of the CFRP reinforcement adopted.

\begin{tabular}{lllll}
\hline Type & Density & Thickness & Tensile strength & Young mod. \\
\hline Mapewrapt C & $1820 \mathrm{~kg} / \mathrm{m}^{3}$ & $0.329 \mathrm{~mm}$ & $4410 \mathrm{MPa}$ & $390000 \mathrm{MPa}$ \\
UNI-AX HM 600 & & & & \\
\hline
\end{tabular}




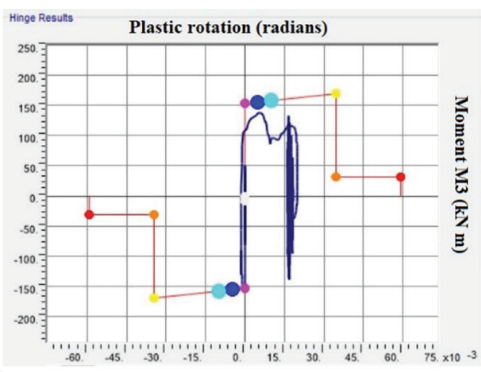

(a)

Figure 8: Column plastic hinge behaviour: (a) pre-retrofit and (b) post-retrofit (from SAP2000).

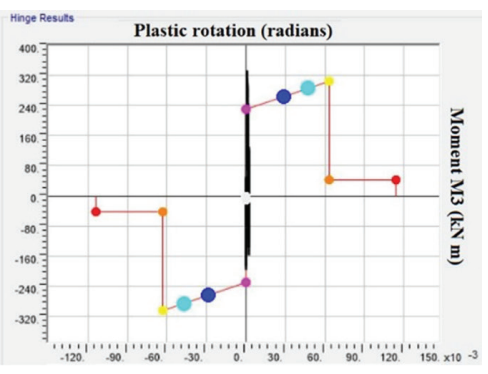

(b) 

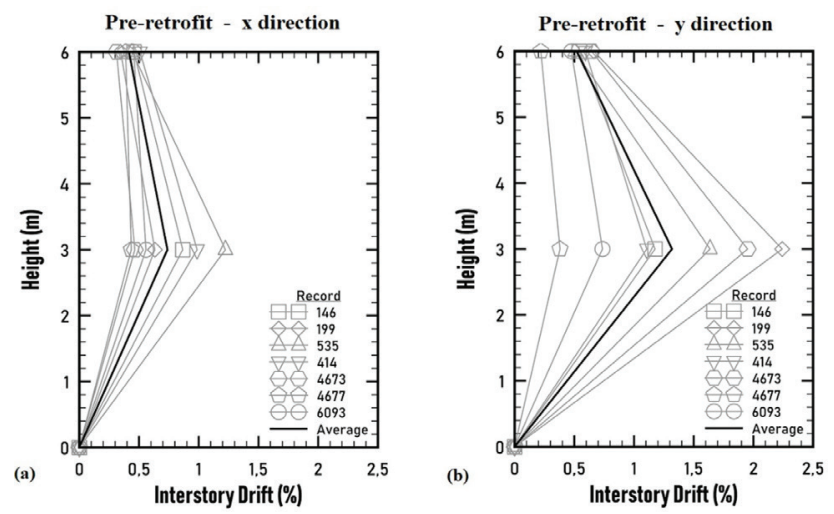

Figure 10: Maximum interstorey drift of the pre-retrofit building in the (a) $x$-direction and (b) $y$-direction under the seven earthquakes of the suite (from SeismoStruct).
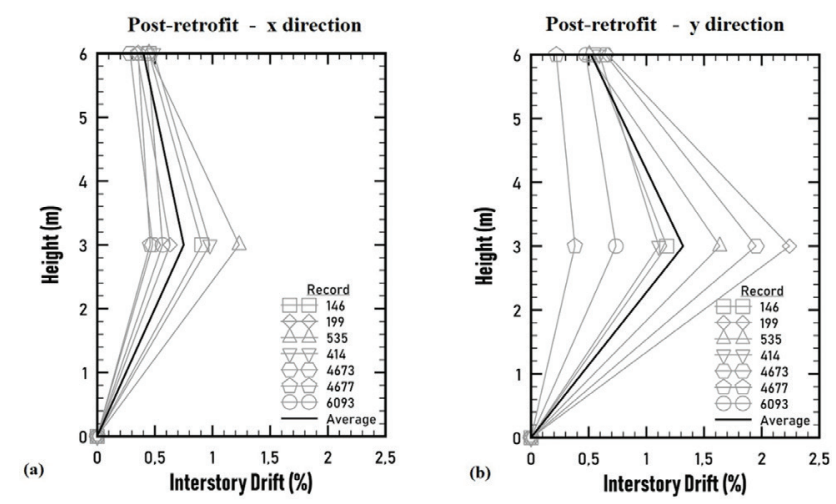

Figure 11: Maximum interstorey drift of the post-retrofit building in the (a) $x$-direction and (b) $y$-direction under the seven earthquakes of the suite (from SeismoStruct).

does not increase the overall stiffness, but it only adds additional strength to the ends of the columns improving the whole seismic performance of the building, also in terms of ductility.

\section{CONCLUSIONS}

The seismic retrofit of pre-code existing buildings can be carried out through a tree-step procedure based on successive non-linear dynamic analyses. Such steps allow one (1) to preliminarily assess the seismic performance of the existing building, highlighting any likely sub-standard behaviour of its members; (2) to choose a suitable retrofit strategy to improve the seismic behaviour of the building; (3) to check the effectiveness of the retrofit strategy under strong earthquakes. This paper showed how this procedure can be applied to a pre-seismic-code reinforced-concrete building seismically retrofitted through CFRP wrapping at the end sections of ground floor columns. A suite of seven spectrum consistent earthquakes referring to the high-seismicity area of Messina (Italy) was considered in the study. The NLTH analyses were carried out in parallel through two advanced structural programmes: SAP2000 and SeismoStruct. Some results of the investigation are listed below. 
- The NLTH analysis highlighted that the pre-code Italian building exhibits a soft-storey mechanism caused by the unfulfilment of the hierarchy of moment strengths at the end of the columns of the ground floor.

- The effectiveness of the seismic retrofit strategy, based on CFRP wrapping of the end sections of the ground floor columns, was checked through the NLTH analysis. A strong-column weak-beam mechanism is finally exhibited by the post-retrofit building modelled with SAP2000, as in fact it is desirable. On the contrary, when analyzed through Seismostruct, the post-retrofit building still exhibited a soft-storey mechanism.

- SeismoStruct is more suitable than SAP2000 to carry out the NLTH analysis of the post-retrofit building, since it allows one to model directly the CFRP reinforcement. A preliminary time-consuming external analysis is needed to model the CFRP wrapped sections in SAP2000 instead, which can make the NLTH analysis of the retrofitted building lengthy and not reliable enough.

- Provided that a suitable structural program is adopted, the three-step procedure based on the NLTH analysis was shown to be very effective when the seismic performance of a precode existing building should be assessed, and its seismic retrofit planned.

Further investigations are underway to compare the present results with those obtained by means of an approach based on pushover analyses as well as to check the efficacy of the procedure when irregular buildings are involved or different retrofit strategies are adopted.

\section{ACKNOWLEDGEMENTS}

Eng. Melcagni and Mapei spa (www.mapei.it) are acknowledged. This work was partially supported by Fondazione Sardegna (University of Cagliari, Italy) and School of Civil Engineering of Pontificia Universidad Católica de Valparaíso, Chile.

\section{REFERENCES}

[1] Porcu, M.C., Bosu, C. \& Gavrić, I., Non-linear dynamic analysis to assess the seismic performance of cross-laminated timber structures. Journal of Building Engineering, 19, pp. 480-493, 2018. https://doi.org/10.1016/j.jobe.2018.06.008

[2] Carvalho, G., Bento, R. \& Bhatt, C., Nonlinear static and dynamic analyses of reinforced concrete buildings-comparison of different modelling approaches. Earthquake and Structures, 4(5), pp. 451-470, 2013. https://doi.org/10.12989/eas.2013.4.5.451

[3] Porcu, M.C., Code inadequacies discouraging the earthquake-based seismic analysis of buildings. International Journal of Safety and Security Engineering, 7(4), pp. 545-556, 2017. https://doi.org/10.2495/safe-v7-n4-545-556

[4] Mazza, F., Mazza, M. \& Vulcano, A., Base-isolation systems for the seismic retrofitting of rc framed buildings with soft-storey subjected to near-fault earthquakes. Soil Dynamics and Earthquake Engineering, 109, pp. 209-221, 2018. https://doi.org/10.1016/j.soildyn.2018.02.025

[5] Porcu, M.C., Partial floor mass isolation to control the seismic stress in framed buildings. International Journal of Safety and Security Engineering, 9(2), pp. 157-165, 2019. doi: 10.2495/SAFE-V9-N2-157-165

[6] Porcu, M.C., Numerical assessment of a stress control method based on rigid-plastic inertia-limiters. Proceedings of the Fourteenth International Conference on Civil, Structural and Environmental Engineering Computing. eds. B.H.V. Topping \& P. Iványi, Civil-Comp Press, 2013. https://doi.org/10.4203/ccp.102.42 
[7] Ghiani, C., Linul, E., Porcu, M.C., Marsavina, L., Movahedi, N. \& Aymerich, F., Metal foam-filled tubes as plastic dissipaters in earthquake-resistant steel buildings. In IOP Conference Series: Materials Science and Engineering, 416(1), 2018. https://doi. org/10.1088/1757-899x/416/1/012051

[8] Symans, M.D., Charney, F.A., Whittaker, A.S., Constantinou, M.C., Kircher, C.A., Johnson, M.W. \& McNamara, R.J., Energy dissipation systems for seismic applications: current practice and recent developments. Journal of Structural Engineering, 134(1), pp. 3-21, 2008. https://doi.org/10.1061/(asce)0733-9445(2008)134:1(3)

[9] Porcu, M.C., Ductile behavior of timber structures under strong dynamic loads. In Wood in Civil Engineering. InTech, 2017. https://doi.org/10.5772/65894

[10] CEN. Eurocode 8: Design of Structures for Earthquake Resistance - Part 1: General Rules, Seismic Actions and Rules for Buildings. European Comitee for Standardization, Brussels, p. 232, 2004.

[11] Iacobucci, R.D., Sheikh, S.A. \& Bayrak, O., Retrofit of square concrete columns with carbon fiber-reinforced polymer for seismic resistance. Structural Journal, 100(6), pp. 785-794, 2003. https://doi.org/10.14359/12845

[12] CSI, SAP2000 v.20. Integrated Finite Element Analysis and Design of Structures Basic Analysis Reference Manual, Computers and Structures, Inc., Berkeley, Cal., USA, 2016.

[13] SeismoSoft., SeismoStruct 2016-A computer program for static and dynamic nonlinear analysis of framed structures, available from http://www.seismosoft.com

[14] Vielma, J.C., Barbat A. \& Oller, S., Seismic response of the RC framed buildings designed according to Eurocodes. Chapter in Computational Methods in Earthquake Engineering. Springer. Heildelberg. Germany. ISBN: 978-94-007-0052-9, 2010.

[15] Vielma, J.C. \& Mulder, M., Assessment of the response reduction factors of planirregular RC buildings. WIT Transactions on the Built Environment, 172, pp. 47-57, 2017. https://doi.org/10.2495/eres170051

[16] Vielma, J.C., Barbat, A.H. \& Oller, S., Seismic safety of low ductility structures used in Spain. Bulletin of Earthquake Engineering, 8(1), pp. 135-155, 2010. https://doi. org/10.1007/s10518-009-9127-4

[17] Vielma, J.C., Barbat A.H. \& Oller, S., Seismic performance of buildings with waffledslab floors. Proceedings of the Institution of Civil Engineers - Structures and Buildings, 162(3), pp. 169-182, 2009. https://doi.org/10.1680/stbu.2009.162.3.169

[18] D.M. 16 Giugno 1976, Norme tecniche per l'esecuzione delle opera in cemento armato normale e precompresso e per le strutture metalliche. In Italian.

[19] FEMA-356, Prestandard Commentary for the Seismic Rehabilitation of Buildings. Federal Emergency Management Agency, Washington, DC, 2000.

[20] Iervolino, I., Galasso, C. \& Cosenza, E., REXEL: computer aided record selection for code-based seismic structural analysis. Bulletin of Earthquake Engineering, 8(2), pp. 339-362, 2010. https://doi.org/10.1007/s10518-009-9146-1

[21] Ambraseys, N., Smit, P., Douglas, J., Margaris, B., Sigbjörnsson, R., Olafsson, S. \& Costa, G., Internet site for European strong-motion data. Bollettino di Geofisica Teorica ed Applicata, 45(3), pp. 113-129, 2004.

[22] BIAXIAL bending v2.4, 2006. http://www.reluis.it 